https://helda.helsinki.fi

\title{
Parameters governing the performance of electrical mobility spectrometers for measuring sub-3 $\mathrm{nm}$ particles
}

\section{Cai, Runlong}

2019-01

Cai , R , Jiang , J , Mirme , S \& Kangasluoma , J 2019 , ' Parameters governing the performance of electrical mobility spectrometers for measuring sub-3 $\mathrm{nm}$ particles ' , Journal of Aerosol Science , vol. 127 , pp. 102-115 . https://doi.org/10.1016/j.jaerosci.2018.11.002

http://hdl.handle.net/10138/321496

https://doi.org/10.1016/j.jaerosci.2018.11.002

cc_by_nc_nd

acceptedVersion

Downloaded from Helda, University of Helsinki institutional repository.

This is an electronic reprint of the original article.

This reprint may differ from the original in pagination and typographic detail.

Please cite the original version. 
3 Parameters governing the performance of electrical mobility spectrometers for measuring

4

5

6

7

8

9

10

11

12

13

14

15

16

17

18

19

20

21

22

23

24

25

sub-3 nm particles

.

Runlong Cai ${ }^{\mathrm{a}, \mathrm{b}^{*}}$, Jingkun Jiang ${ }^{\mathrm{a}}$, Sander Mirme ${ }^{\mathrm{c}}$, and Juha Kangasluoma ${ }^{\mathrm{b}, \mathrm{d}}$

a State Key Joint Laboratory of Environment Simulation and Pollution Control, School of 列 Environment, Tsinghua University, 100084 Beijing, China;

${ }^{\mathrm{b}}$ Institute for Atmospheric and Earth System Research / Physics Faculty of Science, University of . Helsinki, P.O. Box 64, 00014 Helsinki, Finland

c Institute of Physics, Laboratory of Environmental Physics, University of Tartu, Ülikooli 18, EE50090 Tartu, Estonia

d Aerosol and Haze Laboratory, Beijing Advanced Innovation Center for Soft Matter Science and Engineering, Beijing University of Chemical Technology, 100029 Beijing, China 17 8

October 25, 2018 
Measuring aerosol size distributions accurately down to $\sim 1 \mathrm{~nm}$ is a key to nucleation studies, and it requires developments and improvements in instruments such as electrical mobility spectrometers in use today. The key factors characterizing the performance of an electrical mobility spectrometer for sub-3 nm particles are discussed in this study. A parameter named as $\Pi$ is proposed as a figure of merit for the performance of an electrical mobility spectrometer in the sub-3 $\mathrm{nm}$ size range instead of the overall detection efficiency. $\Pi$ includes the overall detection efficiency, the measurement time in each size bin, the aerosol flow rate passing through the detector, and the aerosol-to-sheath flow ratio of the differential mobility analyzer. The particle raw count number recorded by the detector can be estimated using $\Pi$ at a given aerosol size distribution function, $\mathrm{d} N / \mathrm{dlog} d_{p}$. The limit of detection for the spectrometer and the statistical uncertainty of the measured aerosol size distribution can also be readily estimated using $\Pi$. In addition to $\Pi$, the size resolution of an electrical mobility analyzer is another factor characterizing the systematic errors originated from particle sizing. Four existing electrical mobility spectrometers designed for measuring sub-3 $\mathrm{nm}$ aerosol size distributions, including three scanning/differential mobility particle spectrometers and one differential mobility analyzer train, are examined. Their optimal performance is evaluated using $\Pi$ and the size resolution.

42 For example, the $\Pi$ value and the size resolution of a diethylene-glycol differential mobility particle spectrometer for $1.5 \mathrm{~nm}$ particles are $8.0 \times 10^{-4} \mathrm{~cm}^{3}$ and 5.7, respectively. The corresponding relative uncertainty of the measured size distribution is approximately $9.6 \%$ during an atmospheric new particle fromation event with a $\mathrm{d} N / \mathrm{d} \log d_{p}$ of $5 \times 10^{5} \mathrm{~cm}^{-3}$. Assuming an adjustable sheath flow rate of the differential mobility analyzer, the optimal size resolution is approximately 5-9 when measuring 47 atmospheric new particle formation events.

48 Keywords: electrical mobility spectrometer; sub-3 nm particles; penetration efficiency; resolution; uncertainty; aerosol size distribution 
51 Measuring aerosol size distributions down to the cluster size $(1.5 \pm 0.4 \mathrm{~nm})$ lays the foundation for understanding the mechanisms of atmospheric new particle formation (Almeida et al. 2013; Chen et al. 2012; Kulmala et al. 2012). Gaseous precursors in atmospheric environments form molecular clusters via random collisions, and the clusters subsequently grow via condensational growth into larger particles if they are sufficiently stable (Zhang et al. 2012) and are not scavenged by larger particles due to coagulation (Kerminen, Pirjola and Kulmala 2001; McMurry 1983). Measuring particles accurately down to the cluster size has been a challenging task, yet recent progresses in their measurements have provided insights into atmospheric new particle formation (e.g., Kirkby et al. 2016; Sipilä et al. 2016). In addition, sub-3 nm processes in industrial applications have been recently studied with new measurements (Alanen et al. 2015; Nosko, Vanhanen and Olofsson 2016; Tang et al. 2017).

Developments of sub-3 nm particle measurement techniques in the past decade have made it feasible to observe aerosol size distributions down to cluster sizes at ambient concentrations. Iida, Stolzenburg and McMurry (2009) proposed to use diethylene glycol (DEG) as the particle counter working fluid, which helped to extend the lower size limit of the ultrafine condensation particle counter (UCPC, Stolzenburg and McMurry 1991) and the particle size magnifier (PSM, Kim, Okuyama and Fernández de la Mora 2003; Kogan and Burnasheva 1960; Okuyama, Kousaka and Motouchi 1984; Vanhanen et al. 2011) down to $1 \mathrm{~nm}$. Using a DEG-UCPC as the particle detector, a DEG-scanning mobility size spectrometer (DEG-SMPS, Jiang et al. 2011b) can measure sub-3 nm aerosol size distributions during atmospheric new particle formation events (Cai et al. 2017b; Jiang et al. 2011c). Compared to instruments using other techniques to measure sub-3 nm aerosol size distributions, e.g., the pulseheight CPC (Kuang 2018; Sipilä et al. 2008; Sipilä et al. 2009; Weber et al. 1998), the scanning PSM 73 (Lehtipalo et al. 2014; Vanhanen et al. 2011), the neutral cluster and air ion spectrometer (NAIS, 74 Manninen et al. 2009), and the symmetric inclined grid mobility analyzer (Tammet 2011), an 
electrical mobility spectrometer using a CPC as the detector usually has a higher size resolution and lower background noise.

However, the current electrical mobility spectrometers for sub-3 nm particles still need improvements towards higher temporal resolutions, higher size resolutions, higher sensitivities with respect to aerosol size distributions, and lower uncertainties in atmospheric conditions. The sampling efficiency, aerosol charge fraction, the penetration efficiencies through the charger and the differential mobility analyzer (DMA), and the detection efficiency of the CPC decrease sharply with decreasing particle size in sub-2 $\mathrm{nm}$ size range (Jiang et al. 2011b). These low efficiencies limit the overall detection efficiency of an electrical mobility spectrometer, leading to high limits of detection (LODs) and large uncertainties at typical atmospheric particle number concentrations. As a result, the concentration of the newly formed particles may not surpass the LOD of the instrument. For example, the DEG-SMPSs recorded only several raw counts when measuring $~ 1.3 \mathrm{~nm}$ particles in two reported campaigns (Cai et al. 2017b; Jiang et al. 2011c) during relatively strong new particle formation events (dN/dlog $d_{p}>$ $10^{5} \mathrm{~cm}^{-3}$ ). The unknown chemical composition of ambient new particles, together with the assumed charge fractions for sub-3 nm particles, also causes non-negligible uncertainties (Jiang et al. 2011b; Kangasluoma and Kontkanen 2017; Kangasluoma et al. 2016b).

Several improvements in the electrical mobility spectrometers for measuring sub-3 nm particles have been suggested recently. Sampling from the core of the flow minimizes the particle losses in the sampling line (Kangasluoma et al. 2016a). A miniature cylindrical DMA operating at a medium sheath flow rate (20-30 liters per minute) was developed to improve the penetration efficiency and size resolution for sub-3 nm particles (Cai et al. 2017a). A supercritical DMA working at reduced aerosol and sheath flow rates (Cai et al. 2018a; Fernández de la Mora 2017) was recently applied to improve the size resolution of a differential mobility particle spectrometer (Kangasluoma et al. 2018). A new DMA (TSI Inc., model 3086) to classify particles down to 1 nm was developed and used for the commercialized DEG-SMPS system (Stolzenburg et al. 2018). A DMA-train composed of six 
DMAs operating in parallel at fixed but different particle sizes was developed to improve the temporal resolution (Stolzenburg, Steiner and Winkler 2017).

However, the overall detection efficiency together with the size resolution as reported in previous studies (e.g., Jiang et al. 2011b; Kangasluoma et al. 2018; Stolzenburg, Steiner and Winkler 2017) cannot fully characterize the potential improvements to the instruments in the sub-3 $\mathrm{nm}$ size range. Increasing the raw count number recorded by the detector CPC will reduce the statistical uncertainty and the LOD. Therefore, increasing the measurement time in each size bin and the aerosol flow rate passing through the detector will also increase the raw count number and hence improve the instrument performance (Iida 2008). Thus, one should also take the measurement time and the aerosol flow rate passing through the detector into account when evaluating the performance of an electrical mobility spectrometer. Furthermore, a high size resolution is preferred to obtain more accurate aerosol size distributions, whereas the relationship between size resolution and the systematic errors of the inverted sub-3 $\mathrm{nm}$ aerosol size distribution originated from uncertainties in particle sizing has not been quantitatively discussed before.

In this study, we propose a $\Pi$ parameter, i.e., a product including the overall particle detection efficiency, the measurement time in each size bin, the aerosol flow rate passing through the detector, and the integral of DMA transfer function with respect to particle diameter, as a figure of merit for characterizing the performance of an electrical mobility spectrometer for sub-3 nm particles instead of the overall detection efficiency $(P)$. Four existing electrical mobility spectrometers are theoretically compared to illustrate the advantage of $\Pi$ over $P$. The influence of $\Pi$ and the size resolution on the uncertainty of the inverted sub-3 nm aerosol size distribution is theoretically analyzed. The feasibility of using a Faraday cage electrometer (FCE) instead of a CPC as the detector of an electrical mobility spectrometer and the systematic error of a scanning PSM are also discussed based on analyses using $\Pi$ and the size resolution. 


\subsection{Definition of $\Pi$}

A typical electrical mobility spectrometer consists of a sampling line, a charger (neutralizer), a DMA to classify (select) particles with targeted electrical mobility, and a CPC as a detector (Wang and Flagan 1990). Assuming that the DMA sampling flow rate is equal to the aerosol flow rate exiting the DMA, the relationship between the expected value of CPC raw count number and the aerosol size distribution function is:

$$
C^{*}=\int_{-\infty}^{+\infty} P\left(d_{p}\right) \cdot \Omega\left(d_{p}^{*}, d_{p}\right) \cdot n\left(\log d_{p}\right) \cdot t \cdot Q \cdot \operatorname{dlog} d_{p},
$$

where $C^{*}$ is the number of particles counted by the CPC at the DMA centroid electrical mobility diameter, $d_{p}{ }^{*} ; P$ is the overall detection efficiency of the electrical mobility spectrometer (see Eq. 2 below); $\Omega$ is the diffusional DMA transfer function (Stolzenburg 2018; Stolzenburg and McMurry 2008); $n\left(\log d_{p}\right)$ is the aerosol size distribution function (probability density function of particle number concentration) using the logarithm to the base $10, \mathrm{~d} N / \mathrm{dlog} d_{p} ; t$ is the measurement time or averaging time for each size bin; and $Q$ is the effective aerosol flow rate. The effective aerosol flow rate is defined as the equivalent undiluted aerosol flow rate passing through the detector. For example, the effective aerosol flow rate of the DEG-UCPC in Jiang et al. (2011b) is the capillary flow rate (0.03 liter per minute, lpm) rather than the inlet flow rate $(2 \mathrm{lpm})$ or the total flow rate passing through the optical detector $(0.3 \mathrm{lpm})$.

In previous studies (e.g., Jiang et al. 2011b; Stolzenburg, Steiner and Winkler 2017), $P$ is usually determined empirically as the product of the efficiencies for each part of the instrument, i.e.,

$$
P=\eta_{\text {samp }} \cdot \eta_{\text {char }} \cdot f_{\mathrm{c}} \cdot \eta_{\mathrm{DMA}} \cdot \eta_{\mathrm{cpc}} \cdot \eta_{\mathrm{corr}},
$$

where $\eta_{\text {samp }}, \eta_{\text {char }}$, and $\eta_{\text {DMA }}$ are the penetration efficiencies passing through the sampling line, the charger, and the DMA, respectively; $f_{\mathrm{c}}$ is the charge fraction for singly charged particles (the multicharging effect for sub-3 nm particles can be neglected); $\eta_{\text {срс }}$ is the detection efficiency of the CPC; and $\eta_{\text {corr }}$ is a correction factor characterizing additional particle losses due to flow bending (Wang, Flagan and Seinfeld 2002), flow splitting (e.g., 0.8 in Kangasluoma et al. (2018)), and the difference 
between the calibrated and true efficiencies because of the different particle spatial distributions in the flow field for the calibration setup and the electrical mobility spectrometer.

The performance of an electrical mobility spectrometer for sub-3 nm particles was previously characterized using $P$. However, as shown in Eq. 1 , one has to know $t, Q$, and $\Omega$ in addition to $P$ alone to estimate $C^{*}$. In this study, we propose a $\Pi$ parameter as a product of $P, t, Q$, and parameters of the DMA transfer function for better characterizing the performance of an electrical mobility spectrometer. $\Pi$ is defined as:

$$
\Pi=P \cdot t \cdot Q \cdot \beta \cdot\left(-\frac{\mathrm{d} \log d_{p}}{\mathrm{~d} \log Z_{p}}\right),
$$

where $\beta$ is the aerosol-to-sheath flow ratio of the DMA; $Z_{p}$ is the corresponding electrical mobility of particles with the diameter $d_{p}$ and a certain charge. Although $-\operatorname{dlog} d_{p} / \operatorname{dlog} Z_{p}$ is only determined by particle diameter when assuming all the charged sub-3 nm particles can only be singly charged, we include it in the definition of $\Pi$ for a more straightforward relationship between the aerosol size distribution function and the CPC raw count number. According to Eqs. 1 and 3, the relationship between $C^{*}$ and $n\left(\log d_{p}\right)$ can be expressed as:

$$
\begin{aligned}
C^{*} & =\int_{0}^{+\infty} P\left(Z_{p}\right) \cdot \Omega\left(Z_{p}^{*}, Z_{p}\right) \cdot n\left(\log d_{p}\right) \cdot t \cdot Q \cdot\left(-\frac{\mathrm{d} \log d_{p}}{d \log Z_{p}}\right) \cdot \frac{1}{\ln 10} \cdot \frac{1}{Z_{p}} \cdot d Z_{p} \\
& =\frac{\Pi^{*}}{\ln 10 \cdot \beta} \cdot \int_{0}^{+\infty} \frac{P\left(Z_{p}\right)}{P\left(Z_{p}^{*}\right)} \cdot n\left(\log d_{p}\right) \cdot \frac{1}{Z_{p}} \cdot \Omega\left(Z_{p}^{*}, Z_{p}\right) \cdot d Z_{p}
\end{aligned}
$$

where $\Pi^{*}$ and $Z_{p}{ }^{*}$ are the $\Pi$ parameter and the electrical mobility at $d_{p}{ }^{*}$, respectively, and $\operatorname{dlog} d_{p} / \operatorname{dlog} Z_{p}$ is approximated as a constant value in the mobility window of $\Omega$ where $\Omega$ is nonzero (or more specifically, where $\Omega$ is larger than a given small value because $\Omega$ is always nonzero by its expression). Considering that $\int_{0}^{+\infty} \Omega\left(Z_{p}{ }^{*}, Z_{p}\right) \cdot \mathrm{d} Z_{p}=\beta \cdot Z_{p}{ }^{*}$, one can find that $\beta$ and $-\operatorname{dlog} d_{p} / \mathrm{d} \log Z_{p}$ in Eq. 3 actually come from the integral of the diffusional transfer function with respect to dlnd $d_{p}$, i.e., $\int_{-\infty}^{+\infty} \Omega\left(d_{p}^{*}, d_{p}\right) \cdot \mathrm{d} \ln d_{p} \approx-\frac{\mathrm{d} \log d_{p}}{\mathrm{~d} \log Z_{p}} \cdot \beta$. Assuming $P\left(Z_{p}\right), n\left(\log d_{p}\right)$, and $Z_{p}$ are constant values in the 
171 mobility window of $\Omega$, the relationship between $C^{*}$ and $n\left(\log d_{p}\right)$ can be approximated as (Knutson 1976; Stolzenburg and McMurry 2008):

$$
C^{*}=\Pi^{*} \cdot n\left(\log d_{p}^{*}\right) / \ln 10=\Pi^{*} \cdot n\left(\ln d_{p}^{*}\right)
$$

As shown in Eqs. 4 and 5, $\Pi$ is essentially a parameter relating the aerosol size distribution function and the expected value of CPC raw count number. Note that if $t$ remains unchanged, increasing the width of each size bin of an electrical mobility spectrometer cannot increase $C^{*}$ because the fraction of aerosol size distribution function contributing to $C^{*}$ is determined by the DMA transfer function width rather than the bin width.

\subsection{Size resolution and DMA transfer function}

The dimensionless diffusional DMA transfer function is shown in Eq. 6 (Stolzenburg 2018; Stolzenburg and McMurry 2008),

$$
\Omega=\frac{\sigma_{\Omega}}{\sqrt{2} \beta(1-\delta)}\left[\varepsilon\left(\frac{\left(\overline{Z_{p}}-1\right)+\beta}{\sqrt{2} \sigma_{\Omega}}\right)+\varepsilon\left(\frac{\left(\overline{Z_{p}}-1\right)-\beta}{\sqrt{2} \sigma_{\Omega}}\right)-\varepsilon\left(\frac{\left(\overline{Z_{p}}-1\right)+\beta \delta}{\sqrt{2} \sigma_{\Omega}}\right)-\varepsilon\left(\frac{\left(\overline{Z_{p}}-1\right)-\beta \delta}{\sqrt{2} \sigma_{\Omega}}\right)\right]
$$

where $\sigma_{\Omega}$ is the dimensionless diffusion parameter; $\delta$ is the normalized flow imbalance and it is assumed to be zero in this study; $\overline{Z_{p}}$ is the dimensionless electrical mobility, $Z_{p} / Z_{p}{ }^{*}$; and $\varepsilon$ is the error function.

The DMA resolution, $R$, determines the size resolution of an electrical mobility spectrometer. $R$ is defined as the ratio of the centroid electrical mobility to the full width at half-maximum height of the electrical mobility based transfer function (Flagan 1999), i.e.,

$$
R=\frac{Z_{p}^{*}}{\Delta Z_{\mathrm{FWHM}}}
$$

where $\Delta Z_{\text {FWHM }}$ is the full width at half-maximum height of the electrical mobility. One can predict $\sigma_{\Omega}$ and the diffusional transfer function using $R$ at a given $\beta . \sigma_{\Omega}$ can be inferred using Eq. 8 when knowing the $\sigma_{\Omega 0}$ value at any specific electrical mobility, $Z_{p 0}$ (Stolzenburg 2018). 


$$
\sigma_{\Omega}=\sigma_{\Omega 0} \cdot \sqrt{Z_{p} / Z_{p 0}}
$$

194

\subsection{Uncertainties}

Many factors may cause uncertainties/errors in the reported aerosol size distributions, e.g., deviations of the aerosol charge fractions from those calculated using the modified Fuchs theory (Hoppel and Frick 1986) for sub-3 nm particles; randomness in CPC counting; influence of particle chemical composition on the CPC detection efficiency (Jiang et al. 2011b; Kangasluoma and Kontkanen 2017; Kuang et al. 2012); and data inversion methods (Wiedensohler et al. 2012). The cause of CPC measurement uncertainties can be grouped into three main aspects: the statistical uncertainty caused by randomly distributed particles in a given volume which can be predicted using Poisson distribution (Iida 2008; Kangasluoma and Kontkanen 2017; Kuang et al. 2012); the uncertainties linearly proportional to particle concentration, such as the concentration fluctuation due to unstable flow rates and inhomogeneous air mass, which are the dominant uncertainties when the particle raw count number is high; and the CPC background noise due to potential leakage and homogeneous nucleation of the working fluid. In this study, we mainly focus on the CPC statistical uncertainty because it limits the optimal performance of an electrical mobility spectrometer in the sub- $3 \mathrm{~nm}$ size range. The $\Pi$ parameter can also characterize the relationship between $C^{*}$ and $n\left(\log d_{p}\right)$ for particles larger than 3 nm. However, when measuring large particles (e.g., > $25 \mathrm{~nm}$ ), the contribution of statistical uncertainty to the total uncertainties may be negligible due to the correspondingly large $\Pi$, and improving $\Pi$ does not necessarily increase the performance of an electrical mobility spectrometer significantly. The CPC background noise will be accounted for when discussing the LODs. The statistical uncertainty predicted using Poisson distribution is shown in Eq. 9, where $C$ and $\sigma$ are the expected value and the standard deviation of the CPC raw count number, respectively.

$$
\sigma=\sqrt{C}
$$

\section{Methods}




\subsection{Electrical mobility spectrometers}

218 Four existing electrical mobility spectrometers are theoretically compared, including the first prototype DEG-SMPS (Jiang et al. 2011b), an improved version of the DEG-SMPS (Cai et al. 2017a), a differential mobility particle spectrometer (DMPS) using a supercritical DMA working at reduced flow rates (Kangasluoma et al. 2018), and a DMA-train using six DMAs at different fixed voltages with six downstream detectors (Stolzenburg, Steiner and Winkler 2017). In this study, the four instruments are referred as the DEG-SMPS 2011, the DEG-SMPS 2017, the half-mini DMPS, and the DMA-train. The commercialized TSI DEG-SMPS is not included since the penetration efficiency for its DMA has not been reported, yet it can be estimated that the $\Pi$ value of the TSI DEG-SMPS is between the $\Pi$ values of the DEG-SMPS 2011 and the DEG-SMPS 2017.

The specifications of the four instruments are shown in Table 1. Compared to the DEG-SMPS 2011, the DEG-SMPS 2017 improves the sampling efficiency by taking aerosols from the core of sampling flow (Kangasluoma et al. 2016a), deploys a miniature cylindrical DMA (mini-cyDMA) which has higher penetration efficiency and size resolution for sub-3 nm particles (Cai et al. 2017a) compared to the TSI nanoDMA (Chen et al. 1998; Jiang et al. 2011a) in the DEG-SMPS 2011 and increases the capillary flow rate of the DEG-UCPC. The half-mini DMPS also uses the core sampling technique to minimize particle diffusion loss in the sampling line. A supercritical DMA named half-mini DMA 234 (Fernández de la Mora and Kozlowski 2013) with reduced aerosol and sheath flow rates for atmospheric measurements is deployed in the half-mini DMPS. Compared to the DEG-UCPC, the Airmodus PSM has a higher effective aerosol flow rate, $Q$. There are six DMAs working at different 237 but fixed voltages in the DMA train (Stolzenburg, Steiner and Winkler 2017), and we adopt the 238 configurations for the sub-2.5 nm channels in this study. Although using a PSM at a relatively high 239 aerosol flow rate for the initial particle growth, the $Q$ value of the DMA-train is limited by the 240 capillary flow rate of the downstream UCPC. The DMA-train was developed to achieve a high 241 temporal resolution. It can also be used to increase the CPC raw count number by averaging the 
signals during a relatively long time interval (i.e., several minutes). To compare the uncertainties with

243 other instruments at the same temporal resolution, we assume that the averaging time of the DMA244 train is $300 \mathrm{~s}$ in this study. The scanning periods of the DEG-SMPS 2011, the DEG-SMPS 2017, and 245 the half-mini DMPS are all $300 \mathrm{~s}$ in this study, which is a typical scanning period for an SMPS/DMPS 246 in atmospheric measurements considering the scanning speed and the concentration of atmospheric 247 aerosols. The charging properties for sub-3 nm particles are not well understood, and the aerosol 248 charge fractions are different when using radioactive chargers and X-ray chargers due to different ion 249 mobility (Chen and Jiang 2018; Jiang et al. 2014; Lee et al. 2005), yet in this study we simply use a 250 widely used approximation for bipolar charge fractions (Wiedensohler 1988) for all the chargers for 251 the purpose of comparison.

\subsection{Test size distribution}

253 The aerosol size distribution function to examine the uncertainties at different $\Pi$ values and size 254 resolutions is a smoothed distribution obtained from atmospheric measurements (Jiang et al. 2011c). 255 The aerosol size distribution function, $n\left(\log d_{p}\right)$, increases with the decreasing particle diameter (as 256 shown in Fig. 5). Kangasluoma and Kontkanen (2017) estimated the uncertainties in sub-3 nm particle 257 concentration measurements using a similar size distribution. The shape of the test size distribution 258 affects the uncertainties of the measured $n\left(\log d_{p}\right)$. However, since this study mainly focuses on 259 instrumental parameters, we use this distribution function measured during a typical atmospheric new 260 particle formation event alone to illustrate the influence of size resolution on the systematic error due 261 to the uncertainties in particle sizing. The test results using three other distributions including a 262 uniform distribution, a power law distribution, and a lognormal distribution with a peak diameter of $2632 \mathrm{~nm}$ are shown in the supplementary materials.

\subsection{Inversion method}

265 There are various methods to account for the broadening effect of a DMA (Ramachandran and Cooper 2011), i.e., to deal with the Fredholm integral equation of the first kind: 


$$
C^{*}=\int_{-\infty}^{+\infty} \frac{\Pi\left(Z_{p}\right)}{\beta} \cdot n\left(\log d_{p}\right) \cdot \Omega\left(Z_{p}^{*}, Z_{p}\right) \cdot \mathrm{d} \log Z_{p}+P_{\text {rnd }}\left(C^{*}\right),
$$

where $P_{\text {rnd }}\left(C^{*}\right)$ is a random number that follows Poisson distribution with an expected value of $C^{*}$. Note that Eqs. 1, 4, and 10 are essentially the same except for the random error.

The data inversion method to recover aerosol size distributions from CPC raw count number in this study is a one-to-one linear inversion method using Eq. 5, i.e., assuming that $\Pi$ and $n\left(\log d_{p}\right)$ are nearly constant over the mobility window of a given DMA. This one-to-one inversion method was used for DEG-SMPS data inversion in previous studies (e.g., Cai et al. 2017a; Jiang et al. 2011b). A proper inversion method can reduce the uncertainties in the inverted aerosol size distribution. However, some feasible methods previously used in SMPS/DMPS data inversion (such as the inversion routines using the least square method) may magnify the random errors in CPC raw counts into relatively large uncertainties (Enting and Newsam 1990). To constrain random errors, some inversion methods use smoothing steps in the inversion routines (e.g., Markowski 1987) or fit predefined size distribution functions to the data. However, these inversion methods may lead to bias in the shape of the inverted distribution function. Kandlikar and Ramachandran (1999) concluded that there is no single algorithm universally superior to the others. We tested the Hagen \& Alofs method (Hagen and Alofs 1983) and the Expectation-Maximization algorithm (Maher and Laird 1985). When using these two inversion method, the uncertainties are not significantly smaller than using the one-to-one inversion method (Figs. S1 and S2). Thus, we use the one-to-one inversion method in this study for characterizing the relationship between uncertainties and size resolution.

The effect of scan speed on the inverted aerosol size distributions is assumed to be negligible in this study. When operating at a rapid scan speed, an SMPS may broaden and skew the measured aerosol size distributions if the effect of scan speed is not fully considered during data inversion. The finite response time of a CPC (Russell, Flagan and Seinfeld 1995) and the deviation for the static transfer function at a constant voltage from the scanning transfer function (Mai and Flagan 2018) are the major reasons. The broadening and skewing effects are usually significant during rapid scans (e.g., 
scan time $<20$ s, Tröstl et al. 2015). However, to reduce the LODs and uncertainties for sub-3 nm particles, the scan speed is usually limited to obtain a relatively large $\Pi$. For example, if approximating the DEG-UCPC 95\% response time with 1.94 s (Enroth et al. 2018), the $\theta_{\text {s }}$ values (see Russell, Flagan and Seinfeld 1995) for the DEG-SMPS 2011 and the DEG-SMPS 2017 are approximately 0.0075 and 0.0094 , respectively, indicating that neglecting the effect of the scan speed in this study will not lead to significant errors.

\subsection{Analyses}

The analyses conducted in this study are summarized below:

- The $\Pi$ values of the four electrical mobility spectrometers, their particle raw count number at a constant $n\left(\log d_{p}\right)$ of $5 \times 10^{5} \mathrm{~cm}^{-3}$, and the corresponding relative standard deviations;

- The statistical uncertainty and limit of detection as a function of $\Pi$;

- The random errors at different $\Pi$ values when measuring the test distribution;

- The systematic errors at different size resolutions when measuring the test distribution;

- The total uncertainties at different $\Pi$ values and size resolutions;

- The performance of FCE-based electrical mobility spectrometers and a scanning PSM characterized using $\Pi$ and size resolution.

\section{Results and discussion}

\subsection{II parameter}

The $\Pi$ parameter characterizes the performance of an electrical mobility spectrometer in the sub-3 nm size range better than the overall detection efficiency, P. According to Eqs. 5 and 9, a high CPC raw count number, $C^{*}$, is desirable to reduce the statistical uncertainty, and $C^{*}$ is linearly proportional to $П . P$ is usually small for sub-2 $\mathrm{nm}$ particles due to low aerosol charge fractions, low CPC detection efficiencies, and low penetration efficiencies through the sampling line, the charger, and the DMA. However, a relatively small $P$ can be compensated using long measurement time, $t$, and a large aerosol 
flow rate, $Q$. As shown in Fig. 1, the value of $P$ for the half-mini DMPS is lower than or almost the same to the value of $P$ for the DEG-SMPS 2011. However, the half-mini DMPS uses a PSM for the initial particle growth, which increases $Q$ to 19.0 times that of the laminar flow DEG-UCPC in the DEG-SMPS 2011. Thus, the half-mini DMPS has a larger $\Pi$ value hence higher CPC raw counts and smaller statistical uncertainties compared to the DEG-SMPS 2011 when measuring aerosols with the same number concentration. Similarly, although the DMA-train is developed to improve the temporal resolution, its relatively low $P$ values in the sub- $2 \mathrm{~nm}$ particle size range can be compensated if using long averaging time.

The minimum measurement uncertainty, i.e., the statistical uncertainty, of an electrical mobility spectrometer can be estimated using the $\Pi$ parameter. According to Eqs. 5 and 9, the statistical uncertainty is linearly proportional to the square root of $\Pi$ (Fig. 2). For example, the statistical uncertainty of the DEG-SMPS 2017 for $1.5 \mathrm{~nm}$ particles (with a $\Pi$ of $8.04 \times 10^{-4} \mathrm{~cm}^{3}$ ) is $5.4 \%$ when the test $n\left(\log d_{p}\right)$ is $10^{6} \mathrm{~cm}^{-3}$, while the uncertainty increases to $53.5 \%$ when the test $n\left(\log d_{p}\right)$ decreases to $10^{4} \mathrm{~cm}^{-3}$.

The LODs can also be readily estimated using $\Pi$. According to Eq. 5, the LOD of an SMPS/DMPS is determined by $\Pi$ and the background noise of the CPC due to leakage, homogeneous nucleation of the working fluid vapor, and other potential reasons. The background noise of a CPC is usually reported in particle raw count rates or equivalent particle concentrations. For example, the homogeneous nucleation rates of the DEG-SMPS 2011, DEG-SMPS 2017, and the half-mini DMPS are smaller than $0.003,0.003$, and $0.067 \mathrm{~s}^{-1}$, respectively. The reported background concentrations of commercialized CPCs are typically $0.01 \mathrm{~cm}^{-3}$ or smaller. These reported background particle count 337 rates and concentrations are usually average values based on long-time measurements in stable conditions, whereas the false count rates are perhaps larger in practical conditions due to unstable particle sources and environments. Nevertheless, the background noise of a CPC usually does not lead to averagely more than one count in each size bin of an SMPS/DMPS during a scanning cycle 
341 (typically $300 \mathrm{~s}$ for totally 15-30 size bins). Because the CPC count number is always an integer and 342 considering the demand for temporal resolution, it is reasonable to define the LOD of an 343 SMPS/DMPS as the corresponding $\mathrm{d} N / \operatorname{dlog} d_{p}$ when the CPC records only one count (Iida 2008). 344 Accordingly, the LOD of an SMPS/DMPS can be estimated using the formula LOD = 1/П (Fig. 3). 345 Because the statistical uncertainty and LOD of an SMPS/DMPS is a function of $\Pi$, the optimal 346 configuration of an electrical mobility spectrometer should be determined using $\Pi$ rather than $P$. For 347 example, the relationship between the detection efficiency of $1.2 \mathrm{~nm}$ tungsten oxide particles and the 348 inlet flow rate of a tuned butanol CPC for sub-3 nm particles (shown in Fig. 4) was discussed in 349 Kangasluoma et al. (2015). The detection efficiency peak appeared at $~ 1.6$ lpm, which was regarded 350 as the optimal inlet flow rate. For ease of illustration, we assumed this CPC is used as the particle 351 detector of the half-mini DMPS. The peak value of $P$ appears at $\sim 1.6 \mathrm{~nm}$, however, $\Pi$ is still 352 increasing with the increasing $Q$ until $2.2 \mathrm{lpm}$, and the expected value of CPC raw count number at $3532.2 \mathrm{lpm}$ is eventually larger than at $1.6 \mathrm{lpm}$. Thus, the inlet flow rate for the CPC when implemented 354 in the half-mini DMPS should be optimized at $2.2 \mathrm{lpm}$ with a comparatively small $P$ but the largest $355 \Pi$, hence the lowest statistical uncertainty and LOD.

\subsection{Testing the performance of an SMPS/DMPS using $\Pi$ and $R$}

357 In this study, the performance of an electrical mobility spectrometer is characterized by the random 358 error and the systematic error in the measured aerosol size distribution. The random error is the 359 standard deviation of the measured aerosol size distribution and is estimated using the statistical 360 uncertainty. The systematic error is the difference between the test size distribution and the expected 361 value of the inverted size distribution. It originates from uncertainties in particle sizing due to finite 362 size resolution of the electrical mobility spectrometer and potential bias of the inversion method. As 363 discussed in the Method section, we use the one-to-one linear inversion method in this study because 364 it will not magnify the random errors and it is the inversion method currently used in the DEG-SMPSs and the half-mini DMPS. For the test distribution, the expected value of the measured CPC raw count 
number is obtained using Eq. 4 that accounts for the size resolution. The CPC raw number is used as

367 the input of Eq. 5, i.e., the one-to-one linear inversion method, to obtain the inverted size distribution.

368 The difference between the inverted size distribution and the test size distribution is taken as the 369 systematic error. The systematic errors due to uncertainties in aerosol charge fractions and the particle 370 composition dependence of CPC detection efficiencies are not considered here.

371 The total uncertainty of the measured size distribution is characterized using the sum of the absolute 372 value of the systematic error and the random error. The random error and the systematic error are 373 assumed to be independent of each other, i.e., it is assumed that size resolution does not affect the 374 CPC raw count number significantly when estimating the random error. The validity of this 375 assumption was examined for the test distribution and the maximum relative uncertainty of the 376 estimated random error is less than $18 \%$ (when $R=1$ ).

377 The $\Pi$ value mainly affects the random error. Increasing $\Pi$ will reduce the random error when 378 measuring the same aerosol size distribution. For the test distribution, the relative random error of the 379 DEG-SMPS 2011 for $1.3 \mathrm{~nm}$ particles is 30.5\%. When using the DEG-SMPS 2017 which has an 380 improved $\Pi$ value, the relative random error decreases to $15.5 \%$. If one can further improve $\Pi$ to 10 381 times that of the DEG-SMPS 2017, e.g., by improving the aerosol charge fractions, the relative 382 random error can be reduced to 5.0\% (Fig. 5).

383 Improving the size resolution reduces the systematic error. The relative systematic errors at different 384 diameters generally decrease with the increasing size resolution (Fig. 6). For example, the estimated 385 relative systematic errors using the test distribution are $7.5 \%, 3.5 \%$, and $2.0 \%$ when the resolution 386 for $1.5 \mathrm{~nm}$ particles is 3, 5, and 8, respectively. Accordingly, a low size resolution may lead to non387 negligible uncertainties, while higher size resolution (e.g., 7.9 for $1.5 \mathrm{~nm}$ particles if using the halfmini DMPS with reduced flow rates) reduces the systematic errors. 
The aerosol size distribution function also affects the systematic errors; however, the influence is

391 difficult to quantify using simple parameters. The relationships between the relative systematic errors 392 of the inverted size distributions for $1.5 \mathrm{~nm}$ particles and the size resolution when measuring different 393 aerosol size distributions are shown in Fig. S1. All the relative systematic errors decrease with the 394 increasing size resolution.

395 Improving $\Pi$ and the size resolution, $R$, will reduce the uncertainties of the measured aerosol size 396 distribution, as shown in Fig. 7a. The uncertainty is characterized using the sum of the random error 397 (Fig. 5) and the absolute value of the systematic error (Fig. 6). Compared to the DEG-SMPS 2011, 398 the other three instruments improve the optimum performances by increasing $\Pi$ and $R$. For example, 399 the uncertainties of the inverted size distribution at $1.5 \mathrm{~nm}$ are $22.5 \%, 9.4 \%, 8.5 \%$, and $10.5 \%$ when 400 using the DEG-SMPS 2011, the DEG-SMPS 2017, the half-mini DMPS, and the DMA-train, 401 respectively.

402 The $\Pi$ parameter and $R$ can also help to determine the DMA sheath flow configuration. The value of $403 \Pi$ increases with an increasing DMA aerosol-to-sheath flow ratio $(\beta)$; however, the size resolution 404 decreases simultaneously. When varying the sheath flow rate in a reasonable range so that the DMA 405 transfer function is not broadened due to turbulence, one can estimate the uncertainties at different 406 flow configurations and accordingly figure out a an ideal sheath flow rate with a comparatively small 407 uncertainty (see Fig. 7). Decreasing the DMA resolution below approximately 5 to obtain more 408 particle raw counts may increase the total uncertainties at relatively high particle number 409 concentrations due to the increasing systematic error. Conversely, increasing the DMA resolution 410 above approximately 8-9 does not necessarily reduce the systematic errors effectively, while it still 411 lowers the $\Pi$ value and increases the total uncertainties at relatively low particle number 412 concentrations. The optimal size resolution is also affected by the shape of the aerosol size 413 distribution, yet this effect is similar to the effect of particle number concentration. A size distribution 414 corresponding to larger systematic errors and a higher aerosol concentration that causes smaller 
415

random errors both decrease the optimal size resolution. For example, the optimal resolutions corresponding to the minimum uncertainties for the DEG-SMPS 2017, the half-mini DMPS, and the DMA train are 8.6, 8.6, and 8.3 when measuring a lognormal aerosol size distribution, respectively (Fig. S2b), similar to the optimal resolutions for the test distribution but at a higher $\mathrm{d} N / \mathrm{d} \log d_{p}$ of $3 \times 10^{6} \mathrm{~cm}^{-3}$ (Fig. S2c). Thus, we can conclude that the optimal DMA size resolution appears to be $\sim 5$ 9 for $1.5 \mathrm{~nm}$ particles when measuring typical atmospheric new particle formation events and that the improvements to the current electrical mobility spectrometers should come from the improvements in $\Pi$, that is, mainly higher effective aerosol flow rates of the CPCs, higher DMA penetration efficiencies using specially designed DMAs, or improved aerosol charge fractions.

\subsection{FCE-based electrical mobility spectrometers and the scanning PSM}

The FCE-based electrical mobility spectrometers (e.g., the NAIS) and the scanning PSM that measures that total particle concentrations at different supersaturation ratios are also used for sub-3 nm particle measurements. Although their working principles are different from that of a CPC-based electrical mobility spectrometer, the governing factors for their performances can also be analyzed using the $\Pi$ parameter and the size resolution.

The advantage of an FCE over a CPC is that the detection efficiency of the FCE is unaffected by the chemical compositions of the measured particles, while the drawback of the FCE is its comparatively high background noise level. Different from a CPC, the LOD of an FCE is determined as 3 times the root mean square (RMS) value of the noise level based on the average over the measurement time. Zero drift is neglected since we assume that it can be accounted for by tuning the zero offset at the optimal performance. The relationship between the LOD of an FCE-based electrical mobility spectrometer and the $\Pi$ parameter using the current definition is:

$$
\operatorname{LOD}\left(\mathrm{d} N / \mathrm{d} \log d_{p}\right)=\frac{\ln 10 \cdot 3 \cdot \mathrm{RMS}_{1} \cdot \sqrt{t \cdot 1 \mathrm{~s}}}{e \cdot \Pi}
$$


where RMS 1 is the root mean square of the noise level in electric current based on a $1 \mathrm{~s}$ average, $t$ is averaging time, and $e$ is the elementary charge. Perhaps replacing $t$ with $\sqrt{t}$ in the definition of $\Pi$ is more reasonable for an FCE-based electrical mobility spectrometer, yet we used the definition in Eq. 3 for consistency. A new $\Pi$ parameter redefined for an FCE-based electrical mobility spectrometer and its relationship with the statistical error and LOD is discussed in the supplementary materials. Assuming that the CPCs of the four analyzed instruments are replaced with FCEs, the obtained LODs are not low enough to measure atmospheric new particle formation. The aerosol inlet flow rates of the simulated FCEs are assumed the same to the corresponding aerosol flow rate exiting the DMAs so that there is no dilution or bypass flow to reduce $Q$. The root mean square (RMS) of the noise level is assumed to be $0.1 \mathrm{fA}$ based on $1 \mathrm{~s}$ average (Fernández de la Mora et al. 2017), which is a relatively low value among the present commercialized FCEs. The LOD of an imaginary SMPS is also estimated for evaluating the feasibility of measuring sub-3 nm particles using an FCE-based SMPS. We assume $P$ and $\beta$ are the same to those of the half-mini DMPS. The $t$ and $Q$ values of the imaginary SMPS are assumed to be $300 \mathrm{~s}$ and $25 \mathrm{lpm}$, respectively. As shown in Fig. 3b, the four instruments equipped with FCE as detector have too high LODs to measure atmospheric new particle formation events, (e.g., $n\left(\log d_{p}\right)$ was smaller than $\sim 10^{6} \mathrm{~cm}^{-3}$ in Jiang et al. (2011c)), since the LODs are magnitudes higher than the previous configurations using CPCs to detect particles. In addition, the LODs in the sub-1.5 $\mathrm{nm}$ size range in atmospheric measurements may be higher than estimated because of the influence of ions generated in the charger (Kallinger, Steiner and Szymanski 2012). Due to the large values of $t$ and $Q$, the LOD of the imaginary SMPS for sub-2 nm particles approaches typical particle concentration during atmospheric new particle formation events. Assuming a background noise level of $0.01 \mathrm{fA}$ (based on a 4 min average), the LOD of an NAIS can be estimated and is shown in Fig. 3b. The LOD of the NAIS is lower than the FCE-based SMPSs because it uses unipolar corona chargers instead of bipolar chargers and has a higher aerosol flow rate (27 lpm). 
The relatively low size resolution of the scanning PSM limits its accuracy in measuring sub-3 nm

463 particles. Different from an electrical mobility spectrometer, the $\Pi$ value of a scanning PSM is usually 464 sufficiently high because of the high overall detection efficiency $(P)$ due to no need for aerosol 465 charging. The measurement uncertainties of the scanning PSM is mainly determined by instrumental 466 and atmospheric instabilities rather than the statistical uncertainties. Accordingly, $\Pi$ is sufficiently 467 high for the scanning PSM so that improving $\Pi$ may not reduce the uncertainty. The size resolution, 468 however, is one of the limiting factors for the performance of the scanning PSM. The typical size 469 resolution for a scanning PSM ( 1-4, defined differently from the size resolution of an electrical 470 mobility spectrometer) is relatively low (Cai et al. 2018b). As a result, the systematic error of a 471 scanning PSM is larger than typical electrical mobility spectrometers (see Fig. 6c). A proper inversion 472 method may help to reduce the systematic error of a scanning PSM (Cai et al. 2018b), yet the 473 performances of different inversion methods when inverting PSM data from atmospheric 474 measurements need to be further addressed.

\section{Conclusions}

A $\Pi$ parameter including the overall detection efficiency, measurement time, the effective aerosol flow rate, and the aerosol-to-sheath flow ratio of the differential mobility analyzer, is proposed as a figure of merit of an electrical mobility spectrometer for sub-3 nm particles, instead of the overall 479 detection efficiency alone. The statistical uncertainty and the limit of detection of an electrical mobility spectrometer can be estimated using the $\Pi$ parameter. Together with the size resolution, $\Pi$ can characterize the performance of an electrical mobility spectrometer for measuring sub-3 nm particles. A larger $\Pi$ value and a higher size resolution reduce the total uncertainty of the measured aerosol size distribution. Compared to a prototype DEG-SMPS, the other three instruments (the modified DEG-SMPS, the half-mini DMPS, and the DMA-train) improved the $\Pi$ value and the size resolution using different approaches. With the current SMPS/DMPS systems, the optimal DMA size 
The $\Pi$ parameter and the size resolution also help to understand the performance of FCE-based electrical mobility electrometers and scanning PSMs. To overcome the particle composition related activation issue of CPCs, simply replacing the CPC in an existing SMPS/DMPS with an FCE will not provide a sufficiently low detection limit for sub-3 nm particles in typical atmospheric conditions. Thus, one has to improve the instruments towards higher $\Pi$ values if using an FCE as the detector. A scanning PSM benefits from its high $\Pi$ value while the accuracy is limited by the relatively low size resolution.

\section{Conflicts of interest}

There are no conflicts of interest to declare.

\section{Acknowledgement}

Financial supports from the National Key R\&D Program of China (2017YFC0209503), National Science Foundation of China (21876094 \& 41730106), ACTRIS-2 (grant agreement No. 654109), the Academy of Finland (project No. 307331), and Faculty of Science, University of Helsinki, are acknowledged. R. Cai appreciates the support from China Scholarship Council (CSC) for his visit to the University of Helsinki.

\section{References}

Alanen, J., E. Saukko, K. Lehtoranta, T. Murtonen, H. Timonen, R. Hillamo, P. Karjalainen, H. Kuuluvainen, J. Harra, J. Keskinen, T. Rönkkö. 2015. The formation and physical properties of the particle emissions from a natural gas engine. Fuel 162:155-161. doi: 10.1016/j.fuel.2015.09.003.

Almeida, J., S. Schobesberger, A. Kurten, I. K. Ortega, O. Kupiainen-Maatta, A. P. Praplan, A. Adamov, A. Amorim, F. Bianchi, M. Breitenlechner, A. David, J. Dommen, N. M. Donahue, A. Downard, E. Dunne, J. Duplissy, S. Ehrhart, R. C. Flagan, A. Franchin, R. Guida, J. Hakala, A. Hansel, M. Heinritzi, H. Henschel, T. Jokinen, H. Junninen, M. Kajos, J. Kangasluoma, H. Keskinen, A. Kupc, T. Kurten, A. N. Kvashin, A. Laaksonen, K. Lehtipalo, M. Leiminger, J. Leppa, V. Loukonen, V. Makhmutov, S. Mathot, M. J. McGrath, T. Nieminen, T. Olenius, A. Onnela, T. Petaja, F. Riccobono, I. Riipinen, M. Rissanen, L. Rondo, T. Ruuskanen, F. D. Santos, N. Sarnela, S. Schallhart, R. Schnitzhofer, J. H. Seinfeld, M. Simon, M. Sipila, Y. Stozhkov, F. Stratmann, A. Tome, J. Trostl, G. Tsagkogeorgas, P. Vaattovaara, Y. Viisanen, A. Virtanen, A. Vrtala, P. E. Wagner, E. Weingartner, H. Wex, C. Williamson, D. Wimmer, P. Ye, T. Yli-Juuti, K. S. Carslaw, M. Kulmala, J. Curtius, U. Baltensperger, D. R. Worsnop, H. Vehkamaki, J. Kirkby. 2013. 
Molecular understanding of sulphuric acid-amine particle nucleation in the atmosphere. Nature 502:359-363. doi: 10.1038/nature12663.

Cai, R., M. Attoui, J. Jiang, F. Korhonen, J. Hao, T. Petäjä, J. Kangasluoma. 2018a. Characterization of a high-resolution supercritical differential mobility analyzer at reduced flow rates. Aerosol Science and Technology:online available. doi: 10.1080/02786826.2018.1520964.

Cai, R., D.-R. Chen, J. Hao, J. Jiang. 2017a. A miniature cylindrical differential mobility analyzer for sub-3 nm particle sizing. Journal of Aerosol Science 106:111-119. doi: 10.1016/j.jaerosci.2017.01.004.

Cai, R., D. Yang, L. R. Ahonen, L. Shi, F. Korhonen, Y. Ma, J. Hao, T. Petäjä, J. Zheng, J. Kangasluoma, J. Jiang. 2018b. Data inversion methods to determine sub-3 nm aerosol size distributions using the particle size magnifier. Atmospheric Measurement Techniques 11:4477-4491. doi: 10.5194/amt-11-4477-2018.

Cai, R., D. Yang, Y. Fu, X. Wang, X. Li, Y. Ma, J. Hao, J. Zheng, J. Jiang. 2017b. Aerosol surface area concentration: A governing factor in new particle formation in beijing. Atmospheric Chemistry and Physics 17:12327-12340. doi: 10.5194/acp-17-12327-2017.

Chen, D.-R., D. Y. H. Pui, D. Hummes, H. Fissan, F. R. Quant, G. J. Sem. 1998. Design and evaluation of a nanometer aerosol differential mobility analyzer (nano-dma). Journal of Aerosol Science 29:497-509. doi.

Chen, M., M. Titcombe, J. Jiang, C. Jen, C. Kuang, M. L. Fischer, F. L. Eisele, J. I. Siepmann, D. R. Hanson, J. Zhao, P. H. McMurry. 2012. Acid-base chemical reaction model for nucleation rates in the polluted atmospheric boundary layer. Proceedings of the National Academy of Sciences of the United States of America 109:18713-18718. doi: 10.1073/pnas.1210285109.

Chen, X. and J. Jiang. 2018. Retrieving the ion mobility ratio and aerosol charge fractions for a neutralizer in real-world applications. Aerosol Science and Technology:online available. doi: 10.1080/02786826.2018.1498587.

Enroth, J., J. Kangasluoma, F. Korhonen, S. Hering, D. Picard, G. Lewis, M. Attoui, T. Petäjä. 2018. On the time response determination of condensation particle counters. Aerosol Science and Technology 52:778-787. doi: 10.1080/02786826.2018.1460458.

Enting, I. G. and G. N. Newsam. 1990. Atmospheric constituent inversion problems: Implications for baseline monitoring. Journal of Atmospheric Chemistry 11:69-87. doi.

Fernández de la Mora, J. 2017. Expanded flow rate range of high-resolution nanodmas via improved sample flow injection at the aerosol inlet slit. Journal of Aerosol Science 113:265275. doi: 10.1016/j.jaerosci.2017.07.020.

Fernández de la Mora, J. and J. Kozlowski. 2013. Hand-held differential mobility analyzers of high resolution for 1-30nm particles: Design and fabrication considerations. Journal of Aerosol Science 57:45-53. doi: 10.1016/j.jaerosci.2012.10.009.

Fernández de la Mora, J., L. J. Perez-Lorenzo, G. Arranz, M. Amo-Gonzalez, H. Burtscher. 2017. Fast high-resolution nanodma measurements with a $25 \mathrm{~ms}$ response time electrometer. Aerosol Science and Technology 51:724-734. doi: 10.1080/02786826.2017.1296928.

Flagan, R. C. 1999. On differential mobility analyzer resolution. Aerosol Science and Technology 30:556-570. doi: 10.1080/027868299304417.

Hagen, D. E. and D. J. Alofs. 1983. Linear inversion method to obtain aerosol size distributions from measurements with a differential mobility analyzer. Aerosol Science and Technology 2:465-475. doi.

Hoppel, W. A. and G. M. Frick. 1986. Ion-aerosol attachment coefficients and the steady-state charge distribution on aerosols in a bipolar ion environment. Aerosol Science and Technology 5:1-21. doi: 10.1080/02786828608959073. 
Iida, K. 2008. Atmospheric nucleation: Development and application of nanoparticle measurements to assess the roles of ion-induced and neutral processes, University of Minnesota, Minneapolis.

Iida, K., M. R. Stolzenburg, P. H. McMurry. 2009. Effect of working fluid on sub-2 nm particle detection with a laminar flow ultrafine condensation particle counter. Aerosol Science and Technology 43:81-96. doi: 10.1080/02786820802488194.

Jiang, J., M. Attoui, M. Heim, N. A. Brunelli, P. H. McMurry, G. Kasper, R. C. Flagan, K. Giapis, G. Mouret. 2011a. Transfer functions and penetrations of five differential mobility analyzers for sub-2 nm particle classification. Aerosol Science and Technology 45:480-492. doi: 10.1080/02786826.2010.546819.

Jiang, J., M. Chen, C. Kuang, M. Attoui, P. H. McMurry. 2011b. Electrical mobility spectrometer using a diethylene glycol condensation particle counter for measurement of aerosol size distributions down to $1 \mathrm{~nm}$. Aerosol Science and Technology 45:510-521. doi: 10.1080/02786826.2010.547538.

Jiang, J., C. Kim, X. Wang, M. R. Stolzenburg, S. L. Kaufman, C. Qi, G. J. Sem, H. Sakurai, N. Hama, P. H. McMurry. 2014. Aerosol charge fractions downstream of six bipolar chargers: Effects of ion source, source activity, and flowrate. Aerosol Science and Technology 48:1207-1216. doi: 10.1080/02786826.2014.976333.

Jiang, J., J. Zhao, M. Chen, L. F. Eisele, J. Scheckman, J. B. Williams, C. Kuang, H. P. McMurry. 2011c. First measurements of neutral atmospheric cluster and 1-2 nm particle number size distributions during nucleation events. Aerosol Science and Technology (ARL) 45:ii-v. doi: 10.1080/02786826.2010.546817.

Kallinger, P., G. Steiner, W. W. Szymanski. 2012. Characterization of four different bipolar charging devices for nanoparticle charge conditioning. Journal of Nanoparticle Research 14. doi: 10.1007/s11051-012-0944-z.

Kandlikar, M. and G. Ramachandran. 1999. Inversion methods for analyzing aerosol spectrometer measurements: A critical review. Journal of Aerosol Science 30:413-437. doi.

Kangasluoma, J., L. Ahonen, M. Attoui, H. Vuollekoski, M. Kulmala, T. Petäjä. 2015. Sub-3 nm particle detection with commercial tsi 3772 and airmodus a20 fine condensation particle counters. Aerosol Science and Technology 49:674-681. doi: 10.1080/02786826.2015.1058481.

Kangasluoma, J., L. R. Ahonen, T. M. Laurila, R. Cai, J. Enroth, S. B. Mazon, F. Korhonen, P. P. Aalto, M. Kulmala, M. Attoui, T. Petäjä. 2018. Laboratory verification of a new high flow differential mobility particle sizer, and field measurements in hyytiälä. Journal of Aerosol Science 124:1-9. doi.

Kangasluoma, J., A. Franchin, J. Duplissy, L. Ahonen, F. Korhonen, M. Attoui, J. Mikkilä, K. Lehtipalo, J. Vanhanen, M. Kulmala, T. Petäjä. 2016a. Operation of the airmodus a11 nano condensation nucleus counter at various inlet pressures and various operation temperatures, and design of a new inlet system. Atmospheric Measurement Techniques 9:2977-2988. doi: 10.5194/amt-9-2977-2016.

Kangasluoma, J. and J. Kontkanen. 2017. On the sources of uncertainty in the sub-3 nm particle concentration measurement. Journal of Aerosol Science 112:34-51. doi: 10.1016/j.jaerosci.2017.07.002.

Kangasluoma, J., A. Samodurov, M. Attoui, A. Franchin, H. Junninen, F. Korhonen, T. Kurtén, H. Vehkamäki, M. Sipilä, K. Lehtipalo, D. R. Worsnop, T. Petäjä, M. Kulmala. 2016b. Heterogeneous nucleation onto ions and neutralized ions: Insights into sign-preference. The Journal of Physical Chemistry C 120:7444-7450. doi: 10.1021/acs.jpcc.6b01779.

Kerminen, V.-M., L. Pirjola, M. Kulmala. 2001. How significantly does coagulational scavenging limit atmospheric particle production? Journal of Geophysical Research: Atmospheres 106:24119-24125. doi: 10.1029/2001jd000322. 
Kim, C. S., K. Okuyama, J. Fernández de la Mora. 2003. Performance evaluation of an improved particle size magnifier (psm) for single nanoparticle detection. Aerosol Science and Technology 37:791-803. doi: 10.1080/02786820300913.

Kirkby, J., J. Duplissy, K. Sengupta, C. Frege, H. Gordon, C. Williamson, M. Heinritzi, M. Simon, C. Yan, J. Almeida, J. Trostl, T. Nieminen, I. K. Ortega, R. Wagner, A. Adamov, A. Amorim, A. K. Bernhammer, F. Bianchi, M. Breitenlechner, S. Brilke, X. Chen, J. Craven, A. Dias, S. Ehrhart, R. C. Flagan, A. Franchin, C. Fuchs, R. Guida, J. Hakala, C. R. Hoyle, T. Jokinen, H. Junninen, J. Kangasluoma, J. Kim, M. Krapf, A. Kurten, A. Laaksonen, K. Lehtipalo, V. Makhmutov, S. Mathot, U. Molteni, A. Onnela, O. Perakyla, F. Piel, T. Petaja, A. P. Praplan, K. Pringle, A. Rap, N. A. Richards, I. Riipinen, M. P. Rissanen, L. Rondo, N. Sarnela, S. Schobesberger, C. E. Scott, J. H. Seinfeld, M. Sipila, G. Steiner, Y. Stozhkov, F. Stratmann, A. Tome, A. Virtanen, A. L. Vogel, A. C. Wagner, P. E. Wagner, E.

Weingartner, D. Wimmer, P. M. Winkler, P. Ye, X. Zhang, A. Hansel, J. Dommen, N. M. Donahue, D. R. Worsnop, U. Baltensperger, M. Kulmala, K. S. Carslaw, J. Curtius. 2016. Ion-induced nucleation of pure biogenic particles. Nature 533:521-526. doi: 10.1038/nature17953.

Knutson, E. O. 1976. Extended electric mobility method for measuring aerosol particle size and concentration, in Fine particles: Aerosol generation, measurement, sampling, and analysis, Liu, B. Y. H., ed., Academic Press, New York, 739-762.

Kogan, Y. I. and Z. A. Burnasheva. 1960. Growth and measurement of condensation nuclei in a continuous stream. Zhurnal Fizicheskoi Khimii 34:2630-2639. doi.

Kuang, C. 2018. A diethylene glycol condensation particle counter for rapid sizing of sub-3 nm atmospheric clusters (online available). Aerosol Science and Technology. doi: 10.1080/02786826.2018.1481279.

Kuang, C., M. Chen, J. Zhao, J. Smith, P. H. McMurry, J. Wang. 2012. Size and time-resolved growth rate measurements of 1 to $5 \mathrm{~nm}$ freshly formed atmospheric nuclei. Atmospheric Chemistry and Physics 12:3573-3589. doi: 10.5194/acp-12-3573-2012.

Kulmala, M., T. Petäjä, T. Nieminen, M. Sipilä, H. E. Manninen, K. Lehtipalo, M. Dal Maso, P. P. Aalto, H. Junninen, P. Paasonen, I. Riipinen, K. E. Lehtinen, A. Laaksonen, V. M. Kerminen. 2012. Measurement of the nucleation of atmospheric aerosol particles. Nature protocols 7:1651-1667. doi: 10.1038/nprot.2012.091.

Lee, H. M., C. Soo Kim, M. Shimada, K. Okuyama. 2005. Bipolar diffusion charging for aerosol nanoparticle measurement using a soft x-ray charger. Journal of Aerosol Science 36:813829. doi: 10.1016/j.jaerosci.2004.10.011.

Lehtipalo, K., J. Leppä, J. Kontkanen, J. Kangasluoma, A. Franchin, D. Wimmer, S. Schobesberger, H. Junninen, T. Petäjä, M. Sipilä, J. Mikkilä, J. Vanhanen, D. R. Worsnop, M. Kulmala. 2014. Methods for determining particle size distribution and growth rates between 1 and 3 nm using the particle size magnifier. Boreal Environment Research 19:215-236. doi.

Maher, E. F. and N. M. Laird. 1985. Em algorithm reconstruction of particle size distributions from diffusion battery data. Journal of Aerosol Science 16:557-570. doi.

Mai, H. and R. C. Flagan. 2018. Scanning dma analysis: I. Classification transfer function. Aerosol Science and Technology:online available. doi: 10.1080/02786826.2018.1528005.

Manninen, H. E., T. Petäjä, A. Asmi, I. Riipinen, T. Nieminen, J. Mikkilä, U. Hõrrak, A. Mirme, S. Mirme, L. Laakso, V.-M. Kerminen, M. Kulmala. 2009. Long-term field measurements of charged and neutral clusters using neutral cluster and air ion spectrometer (nais). Boreal Environment Research 14:591-605. doi.

Markowski, G. R. 1987. Improving twomey's algorithm for inversion of aerosol measurement data. Aerosol Science and Technology 7:127-141. doi: 10.1080/02786828708959153.

McMurry, P. H. 1983. New particle formation in the presence of an aerosol: Rates, time scales, and sub-0.01 $\mu \mathrm{m}$ size distributions Journal of Colloid and Interface Science 95:72-80. doi. 
Nosko, O., J. Vanhanen, U. Olofsson. 2016. Emission of 1.3-10 nm airborne particles from brake materials. Aerosol Science and Technology 51:91-96. doi: 10.1080/02786826.2016.1255713.

Okuyama, K., Y. Kousaka, T. Motouchi. 1984. Condensational growth of ultrafine aerosol particles in a new particle size magnifier. Aerosol Science and Technology 3:353-366. doi: $10.1080 / 02786828408959024$.

Ramachandran, G. and D. W. Cooper, eds. 2011. Size distribution data analysis and presentation. John Wiley \& Sons, New York.

Russell, L. M., R. C. Flagan, J. H. Seinfeld. 1995. Asymmetric instrument response resulting from mixing effects in accelerated dma-cpc measurements. Aerosol Science and Technology 23:491-509. doi: 10.1080/02786829508965332.

Sipilä, M., K. E. Lehtinen, M. Kulmala, T. Petäjä, H. Junninen, P. Aalto, H. E. Manninen, E.-M. Kyrö, A. Asmi, I. Riipinen, J. Curtius, A. Kürten, S. Borrmann, C. D. O'Dowd. 2008. Applicability of condensation particle counters to measure atmospheric clusters. Atmospheric Chemistry and Physics 8:4049-4060. doi.

Sipilä, M., K. Lehtipalo, M. Attoui, K. Neitola, T. Petäjä, P. P. Aalto, C. D. O'Dowd, M. Kulmala. 2009. Laboratory verification of ph-cpc's ability to monitor atmospheric sub-3 nm clusters. Aerosol Science and Technology 43:126-135. doi: 10.1080/02786820802506227.

Sipilä, M., N. Sarnela, T. Jokinen, H. Henschel, H. Junninen, J. Kontkanen, S. Richters, J. Kangasluoma, A. Franchin, O. Peräkylä, M. P. Rissanen, M. Ehn, H. Vehkamaki, T. Kurten, T. Berndt, T. Petäjä, D. Worsnop, D. Ceburnis, V. M. Kerminen, M. Kulmala, C. O'Dowd. 2016. Molecular-scale evidence of aerosol particle formation via sequential addition of hio3. Nature 537:532-534. doi: 10.1038/nature19314.

Stolzenburg, D., G. Steiner, P. M. Winkler. 2017. A dma-train for precision measurement of sub$10 \mathrm{~nm}$ aerosol dynamics. Atmospheric Measurement Techniques 10:1639-1651. doi: 10.5194/amt-10-1639-2017.

Stolzenburg, M. R. 2018. A review of transfer theory and characterization of measured performance for differential mobility analyzers. Aerosol Science and Technology:online available. doi: 10.1080/02786826.2018.1514101.

Stolzenburg, M. R. and H. P. McMurry. 1991. An ultrafine aerosol condensation nucleus counter. Aerosol Science and Technology 14:48-65. doi.

Stolzenburg, M. R. and P. H. McMurry. 2008. Equations governing single and tandem dma configurations and a new lognormal approximation to the transfer function. Aerosol Science and Technology 42:421-432. doi: 10.1080/02786820802157823.

Stolzenburg, M. R., J. H. T. Scheckman, M. Attoui, H.-S. Han, P. H. McMurry. 2018. Characterization of the tsi model 3086 differential mobility analyzer for classifying aerosols down to $1 \mathrm{~nm}$. Aerosol Science and Technology 52:748-756. doi: 10.1080/02786826.2018.1456649.

Tammet, H. 2011. Symmetric inclined grid mobility analyzer for the measurement of charged clusters and fine nanoparticles in atmospheric air. Aerosol Science and Technology 45:468479. doi: 10.1080/02786826.2010.546818.

Tang, Q., R. Cai, X. You, J. Jiang. 2017. Nascent soot particle size distributions down to $1 \mathrm{~nm}$ from a laminar premixed burner-stabilized stagnation ethylene flame. Proceedings of the Combustion Institute 36:993-1000. doi: 10.1016/j.proci.2016.08.085.

Tröstl, J., T. Tritscher, O. F. Bischof, H.-G. Horn, T. Krinke, U. Baltensperger, M. Gysel. 2015. Fast and precise measurement in the sub-20nm size range using a scanning mobility particle sizer. Journal of Aerosol Science 87:75-87. doi: 10.1016/j.jaerosci.2015.04.001.

Vanhanen, J., J. Mikkilä, K. Lehtipalo, M. Sipilä, H. E. Manninen, E. Siivola, T. Petäjä, M. Kulmala. 2011. Particle size magnifier for nano-cn detection. Aerosol Science and Technology 45:533-542. doi: 10.1080/02786826.2010.547889. 
Wang, J., R. C. Flagan, J. H. Seinfeld. 2002. Diffusional losses in particle sampling systems containing bends and elbows. Journal of Aerosol Science 33:843/857. doi.

Wang, S. C. and R. C. Flagan. 1990. Scanning electrical mobility spectrometer. Aerosol Science and Technology 13:230-240. doi: 10.1080/02786829008959441.

Weber, R. J., M. R. Stolzenburg, S. N. Pandis, H. P. McMurry. 1998. Inversion of ultrafine condensation nucleus counter pulse height distributions to obtain nanoparticle $(\sim 3-10 \mathrm{~nm})$ size distributions. Journal of Aerosol Science 29:601-615. doi.

Wiedensohler, A. 1988. An approximation of the bipolar charge distribution for particles in the submicron size range. Journal of Aerosol Science 19:387-389. doi.

Wiedensohler, A., W. Birmili, A. Nowak, A. Sonntag, K. Weinhold, M. Merkel, B. Wehner, T. Tuch, S. Pfeifer, M. Fiebig, A. M. Fjäraa, E. Asmi, K. Sellegri, R. Depuy, H. Venzac, P. Villani, P. Laj, P. Aalto, J. A. Ogren, E. Swietlicki, P. Williams, P. Roldin, P. Quincey, C. Hüglin, R. Fierz-Schmidhauser, M. Gysel, E. Weingartner, F. Riccobono, S. Santos, C. Grüning, K. Faloon, D. Beddows, R. Harrison, C. Monahan, S. G. Jennings, C. D. O'Dowd, A. Marinoni, H. G. Horn, L. Keck, J. Jiang, J. Scheckman, P. H. McMurry, Z. Deng, C. S. Zhao, M. Moerman, B. Henzing, G. de Leeuw, G. Löschau, S. Bastian. 2012. Mobility particle size spectrometers: Harmonization of technical standards and data structure to facilitate high quality long-term observations of atmospheric particle number size distributions. Atmospheric Measurement Techniques 5:657-685. doi: 10.5194/amt-5-6572012.

Zhang, R., A. Khalizov, L. Wang, M. Hu, W. Xu. 2012. Nucleation and growth of nanoparticles in the atmosphere. Chemical Reviews 112:1957-2011. doi: 10.1021/cr2001756. 
741 Table 1. Specifications of the four electrical mobility spectrometers tested in this study.

\begin{tabular}{|c|c|c|c|c|c|}
\hline Instrument & DMA model & $\begin{array}{l}\text { aerosol-to-sheath flow } \\
\text { ratio (lpm/lpm) }\end{array}$ & Detector model & $\begin{array}{c}t \\
(\mathrm{~s})\end{array}$ & $\begin{array}{c}Q \\
\left(\mathrm{~cm}^{3} / \mathrm{s}\right)\end{array}$ \\
\hline DEG-SMPS 2011 & TSI nanoDMA & $2 / 15$ & DEG-UCPC + TSI 3772 CPC & 20 & 0.60 \\
\hline DEG-SMPS 2017 & Mini-cyDMA & $2.5 / 25$ & DEG-UCPC + TSI 3772 CPC & 8.8 & 4.17 \\
\hline Half-mini DMPS & Half-mini DMA & $5 / 100$ & Airmodus A10 PSM + A20 CPC & 10 & 11.4 \\
\hline DMA-train & GRIMM S-DMA & $2.5 / 25$ & Airmodus A10 PSM + TSI 3776 UCPC & $300^{*}$ & 0.83 \\
\hline
\end{tabular}

742 *: The averaging time of the DMA train is assumed to be $300 \mathrm{~s}$ in this study for the same temporal resolution to the other three 743 instruments.

744 


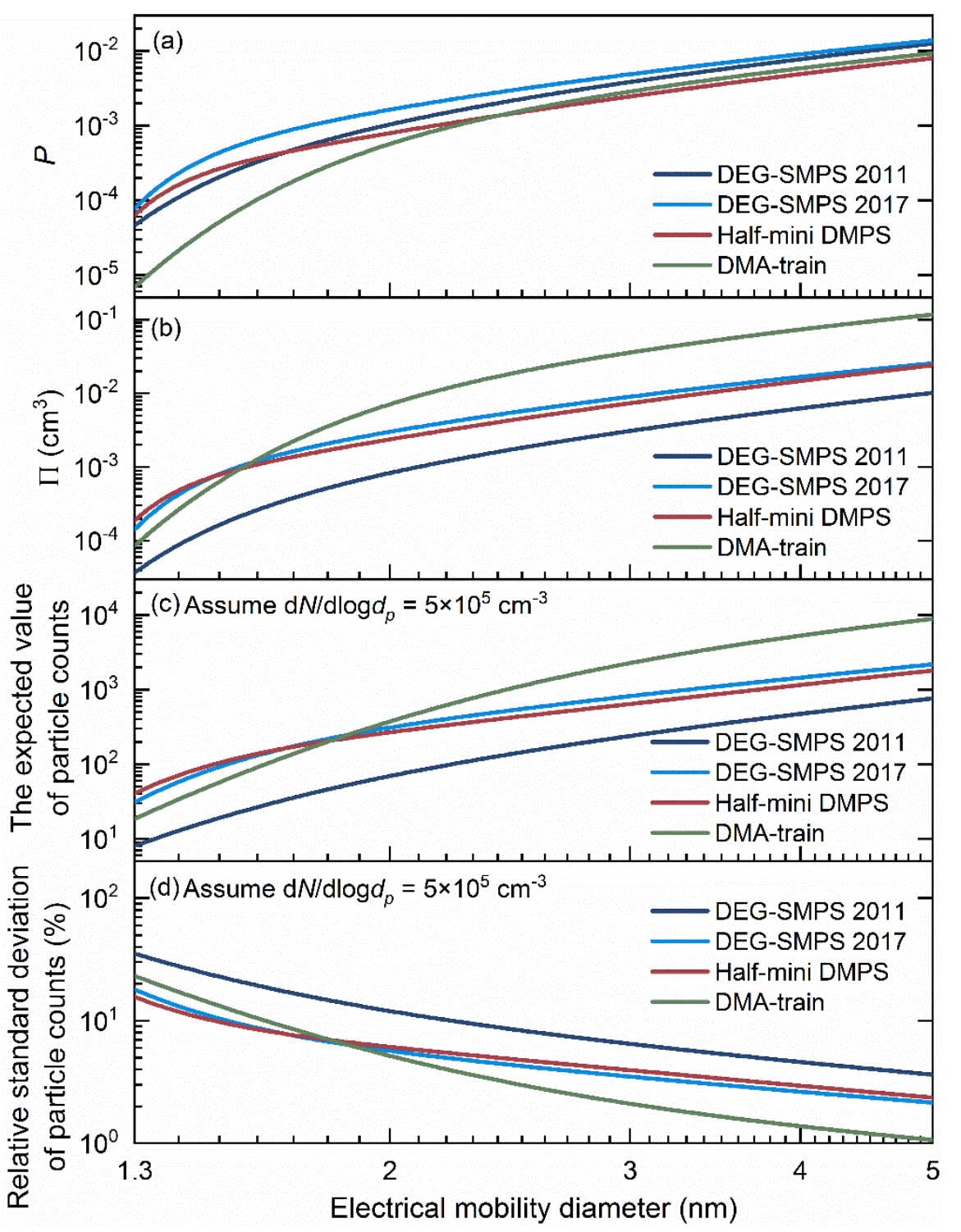

746 Figure 1. (a) The overall detection efficiencies, $P$, (b) the $\Pi$ values, (c) the expected values of particle counts, and

747 (d) the relative standard deviation of particle counts as a function of particle electrical mobility diameters. The 748 aerosol size distribution function, $\mathrm{d} N / \mathrm{d} \log d_{p}$, was assumed to be a constant value of $5 \times 10^{5} \mathrm{~cm}^{-3}$ when estimating 749 the particle raw count number. 


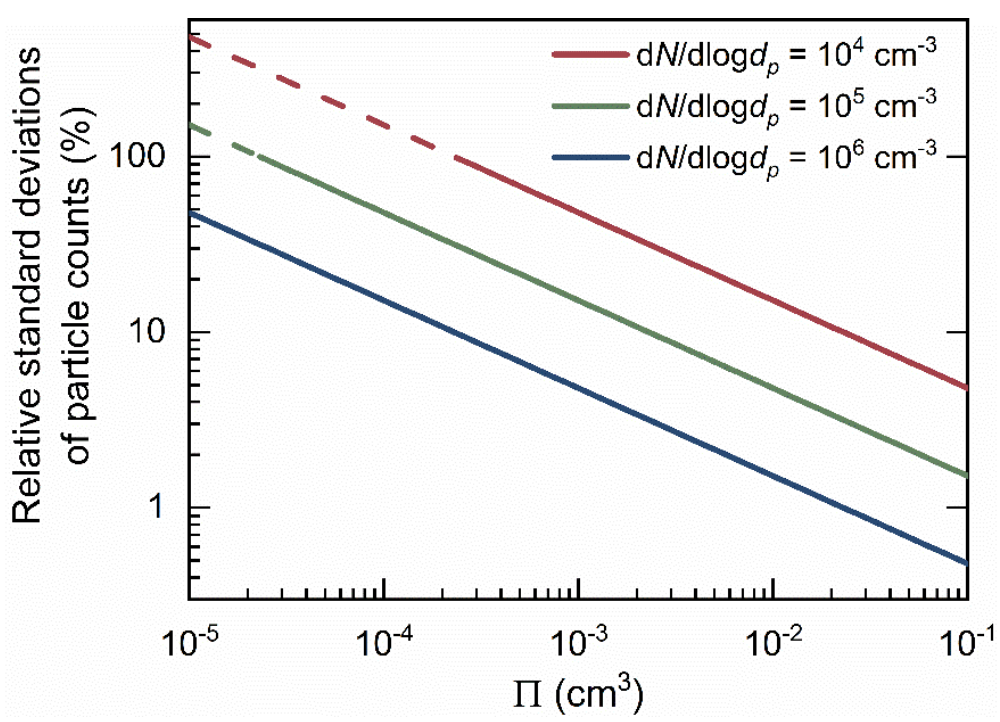

752 Figure 2. The relationship between the relative statistical uncertainty and $\Pi$ at different $\mathrm{d} N / \mathrm{d} \log d_{p}$ levels.

753 Uncertainties larger than 100 percent are shown in dashed lines because the corresponding expected values of 754 particle raw count numbers are smaller than one. 

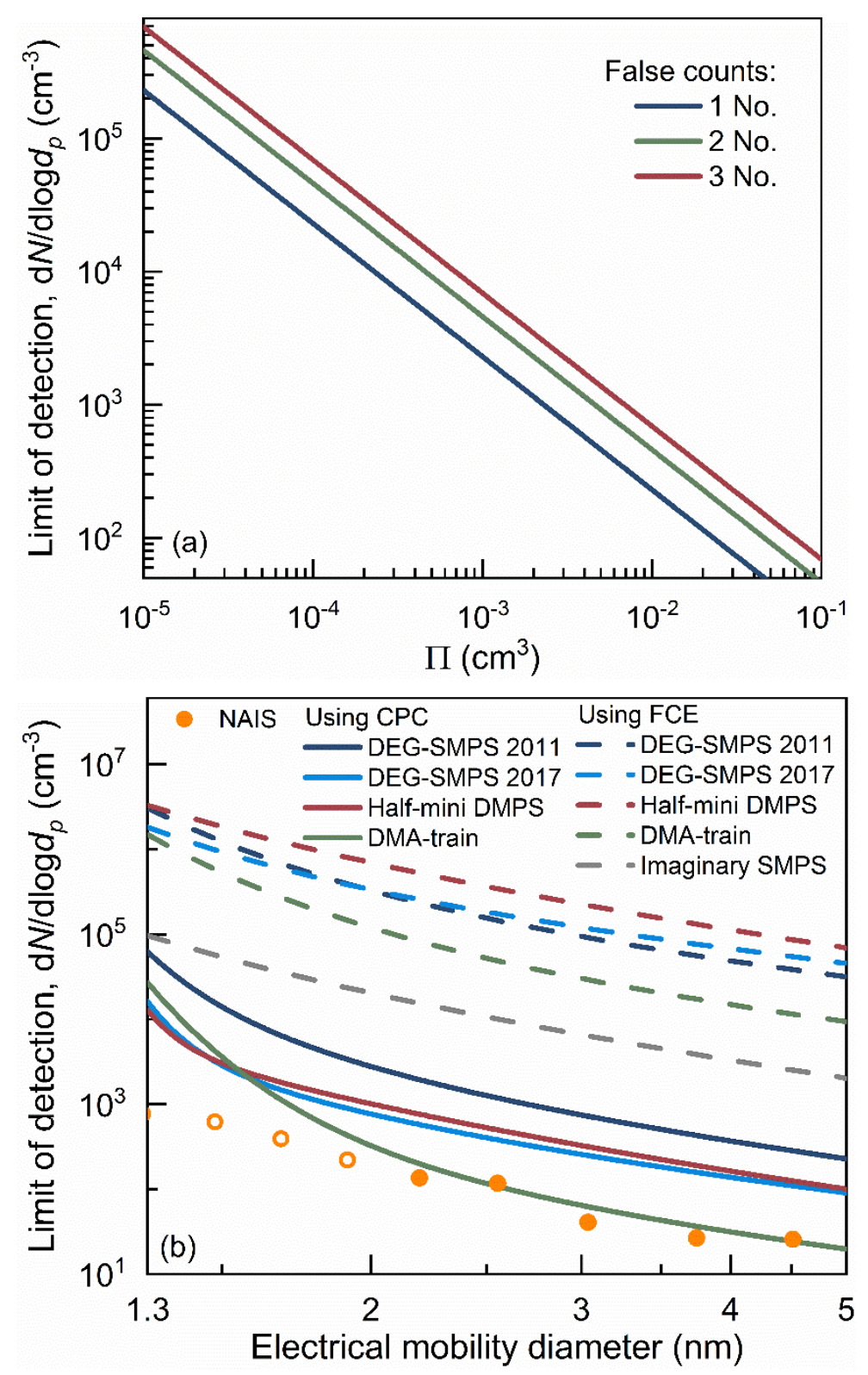

758 Figure 3. (a) The relationship between the limit of detection and the $\Pi$ parameter at different false count levels. The 759 limit of detection is usually determined using one false count, whereas larger false count numbers account for the 760 conditions that there are higher background noises due to homogeneous nucleation of the working fluid and/or 761 unstable particle sources. (b) The estimated limits of detection of different instruments. The limits of detection are determined as the corresponding $\mathrm{d} N / \mathrm{d} \log d_{p}$ values of one single CPC count or three times the root mean square of the FCE noise during the measurement time of each size bin. The representative diameters for the NAIS are the peak diameters of the kernel functions for each size bin. The NAIS data points with diameters smaller than $2 \mathrm{~nm}$ are shown in open circles because that high concentration of ion clusters is often detected in this size range during atmospheric measurements and they are not necessarily related to atmospheric new particle formation. 


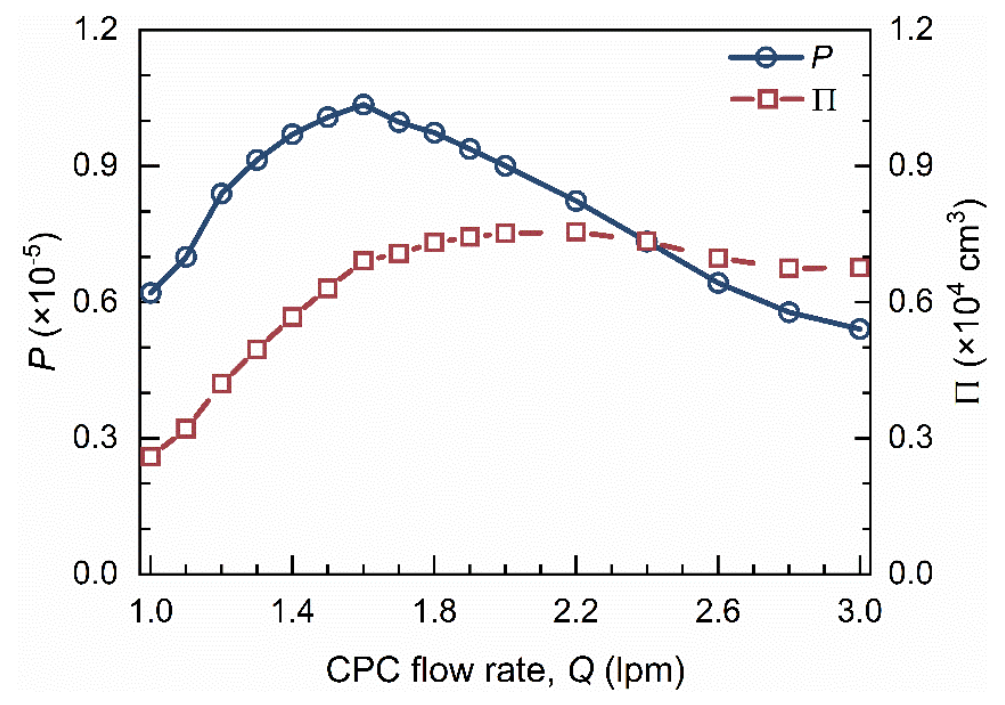

770 Figure 4. The overall detection efficiency, $P$, and the $\Pi$ value for $1.2 \mathrm{~nm}$ negatively charged tungsten oxide particles 771 as a function of the CPC inlet flow rate. The CPC is assumed to be used as the particle detector of the half-mini 772 DMPS for ease of illustration. It is a butanol CPC working at a relatively high background noise level due to the 773 homogeneous nucleation of butanol. The CPC detection efficiencies are adapted from Kangasluoma et al. (2015). 774 Other parameters for estimating $P$ and $\Pi$ are assumed to be independent of the CPC flow rate, e.g., the sampling 775 flow rate and the aerosol flow rate for the DMA at different CPC flow rates are assumed to be a constant value of 5 $776 \mathrm{lpm}$. 


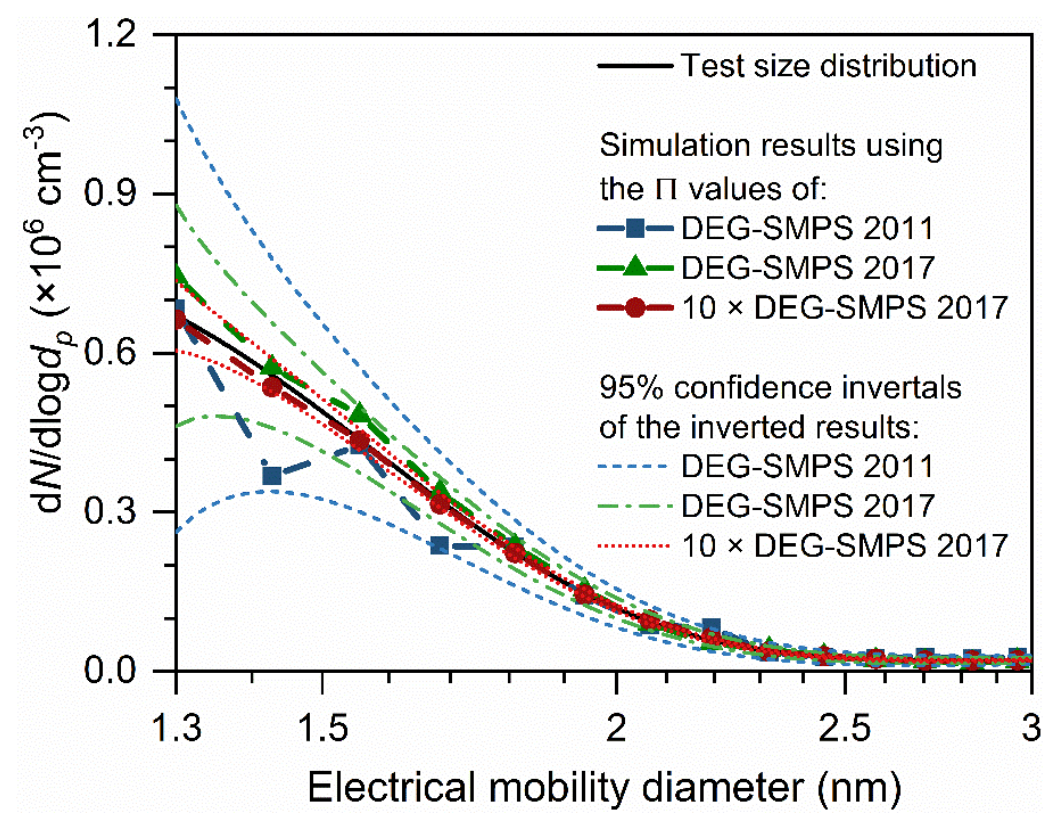

779 Figure 5. The test size distribution and statistical uncertainties at the $\Pi$ values of the DEG-SMPS 2011 and the 780 DEG-SMPS 2017. A large $\Pi$ value 10 times that of the DEG-SMPS 2017 is also included. The effect of size 781 resolution on the inverted particle raw counts is neglected. The Poisson distribution is approximated by a normal 782 distribution. A set of simulation results are shown in scatters as examples. The boundaries for 95\% confidence 783 intervals of the inverted results are indicated. 

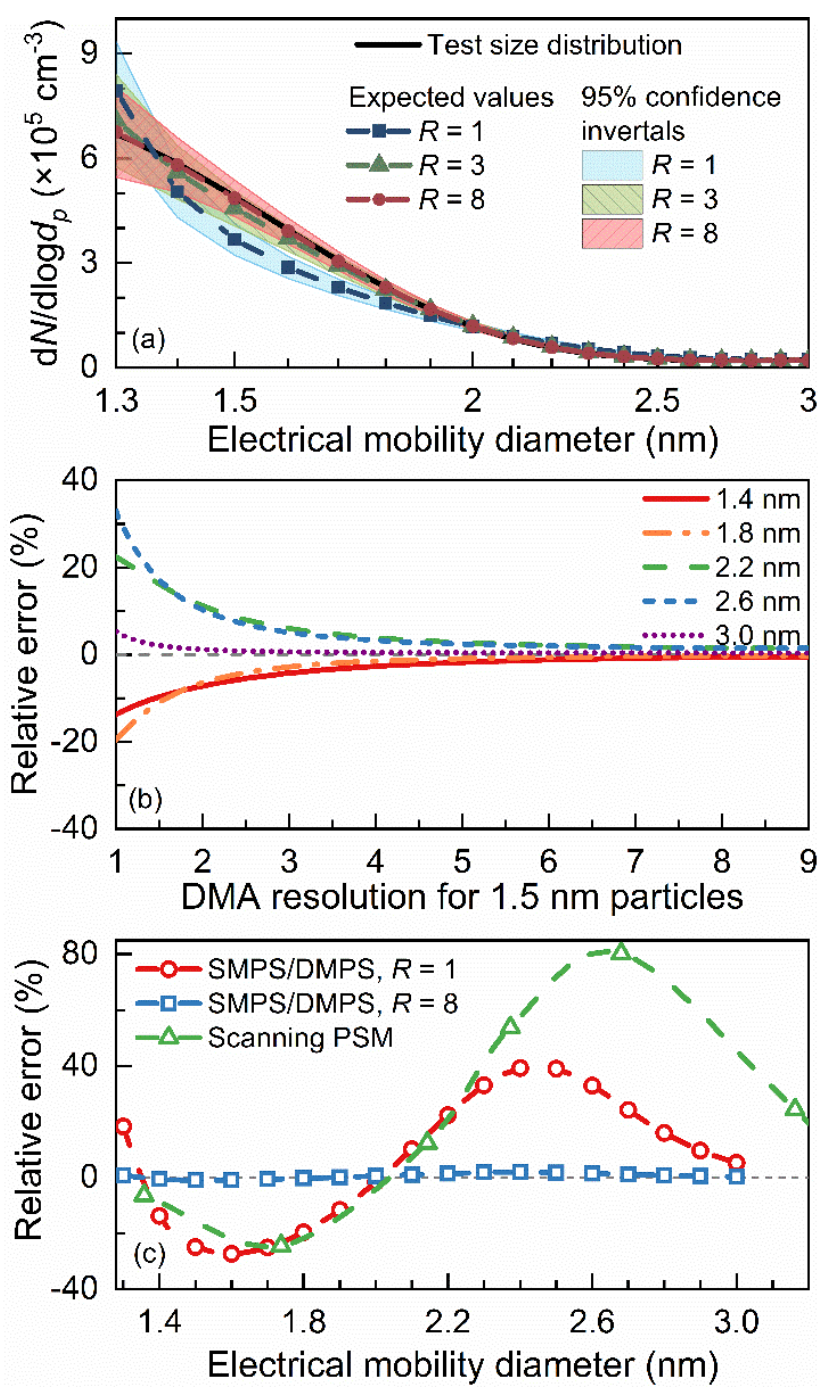

786 Figure 6. The relationship between the relative error of the inverted aerosol size distribution and the size resolution. 787 The size resolutions in the legends indicate the DMA resolutions for $1.5 \mathrm{~nm}$ particles. The resolutions for other 788 electrical mobility diameters are estimated using Eqs. 6, 7, and 8. The test size distribution is the same as the 789 distribution in Fig. 5. (a) The inverted aerosol size distributions at different size resolutions. The shaded areas represent the random errors due to statistical uncertainties estimated using a $\Pi$ value 10 times that of DEG-SMPS 2017. The 95\% confidence intervals are estimated using the normal distribution. Note the probabilities of the inverted $\mathrm{d} N / \mathrm{d} \log d_{p}$ values are not evenly distributed in the shaded areas. (b) The relative systematic errors of the inverted aerosol size distribution at different diameters as a function of the DMA resolution. (c) The relative uncertainties of two electrical mobility spectrometers with different size resolutions and a scanning particle size magnifier. The inversion method for the particle size magnifier is a stepwise method used in commercial instruments (Lehtipalo et al. 2014). 

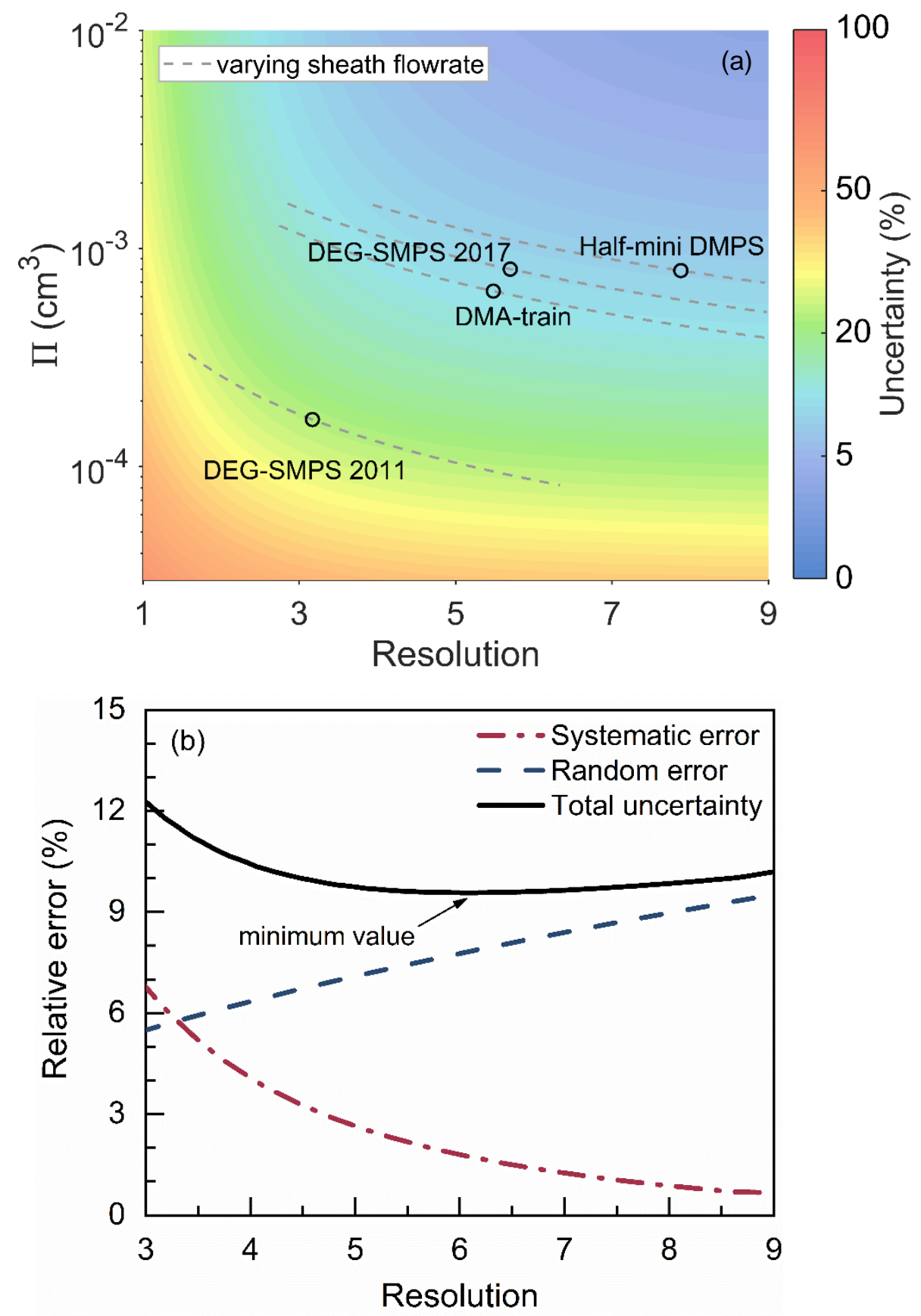

799 Figure 7. (a) The estimated uncertainties of the measured aerosol size distribution as a function of $\Pi$ and the size 800 resolution. The value of uncertainty is indicated by color. The $\mathrm{d} N / \mathrm{d} \log d_{p}$ is equal to that at $1.5 \mathrm{~nm}$ of the test aerosol 801 size distribution in Figs. 5 and $6\left(4.9 \times 10^{5} \mathrm{~cm}^{-3}\right)$. The estimated uncertainties at a lower $\mathrm{d} N / \mathrm{dlog} d_{p}$ value $\left(1 \times 10^{5} \mathrm{~cm}^{-}\right.$ $\left.8023^{3}\right)$ and a higher $\mathrm{d} N / \operatorname{dog} d_{p}$ value $\left(3 \times 10^{6} \mathrm{~cm}^{-3}\right)$ are shown in Fig S4. The size resolutions of the four instruments 803 shown in open circles are the size resolutions for $1.5 \mathrm{~nm}$ particles. The variations of $\Pi$, DMA resolution, and the 804 corresponding uncertainty as a function of the DMA sheath flow rate while maintaining other configurations are 805 indicated using dashed lines. (b) The uncertainty for the DEG-SMPS 2017 as a function of DMA resolution when varying the sheath flow rate, corresponding the dashed line in Fig. 7a. The total uncertainty is characterized by the sum of the systematic error and the random error. 